\title{
REVISED Embryonic zebrafish xenograft assay of human cancer
}

\section{metastasis [version 2; peer review: 2 approved]}

\section{David Hill(11,2, Lanpeng Chen³, Ewe Snaar-Jagalska33, Bill Chaudhry²}

\author{
${ }^{1}$ Institute of Cellular Medicine, Newcastle University, UK, Newcastle upon Tyne, NE2 4HH, UK \\ 2Institute of Genetic Medicine, Newcastle University, UK, Newcastle upon Tyne, NE1 3BZ, UK \\ ${ }^{3}$ Leiden University, Leiden, The Netherlands
}

\section{V2 First published: 22 Oct 2018, 7:1682 \\ https://doi.org/10.12688/f1000research.16659.1}

Latest published: 20 Dec 2018, 7:1682

https://doi.org/10.12688/f1000research.16659.2

\begin{abstract}
Cancer metastasis is the most important prognostic factor determining patient survival, but currently there are very few drugs or therapies that specifically inhibit the invasion and metastasis of cancer cells. Currently, human cancer metastasis is largely studied using transgenic and immunocompromised mouse xenograft models, which are useful for analysing end-point tumour growth but are unable to accurately and reliably monitor in vivo invasion, intravasation, extravasation or secondary tumour formation of human cancer cells. Furthermore, limits in our ability to accurately monitor early stages of tumour growth and detect micro-metastases likely results in pain and suffering to the mice used for cancer xenograft experiments. Zebrafish (Danio rerio) embryos, however, offer many advantages as a model system for studying the complex, multi-step processes involved during cancer metastasis. This article describes a detailed method for the analysis of human cancer cell invasion and metastasis in zebrafish embryos before they reach protected status at 5 days post fertilisation. Results demonstrate that human cancer cells actively invade within a zebrafish microenvironment, and form metastatic tumours at secondary tissue sites, suggesting that the mechanisms involved during the different stages of metastasis are conserved between humans and zebrafish, supporting the use of zebrafish embryos as a viable model of human cancer metastasis. We suggest that the embryonic zebrafish xenograft model of human cancer is a tractable laboratory model that can be used to understand cancer biology, and as a direct replacement of mice for the analysis of drugs that target cancer invasion and metastasis.
\end{abstract}

\section{Keywords}

Zebrafish embryo, xenograft, cancer, melanoma, prostate cancer, metastasis, replacement

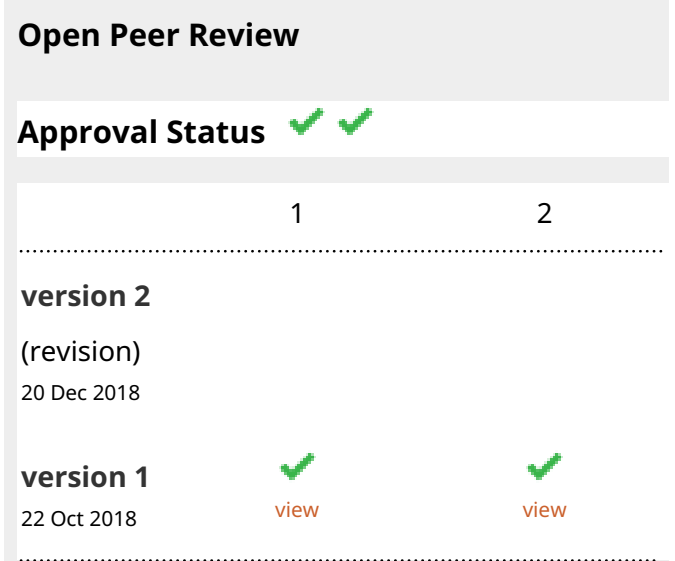

1. Adam Hurlstone, The University of Manchester, Manchester, UK

2. Yi Feng, The University of Edinburgh, Edinburgh, UK

Any reports and responses or comments on the article can be found at the end of the article. 


\section{NC $3 R^{s}$}

This article is included in the NC3Rs gateway.

Corresponding author: David Hill (david.hill5@ncl.ac.uk)

Author roles: Hill D: Conceptualization, Data Curation, Formal Analysis, Funding Acquisition, Investigation, Methodology, Project Administration, Resources, Validation, Visualization, Writing - Original Draft Preparation, Writing - Review \& Editing; Chen L: Data Curation, Formal Analysis, Investigation, Methodology, Writing - Review \& Editing; Snaar-Jagalska E: Conceptualization, Funding Acquisition, Methodology, Project Administration, Supervision, Writing - Review \& Editing; Chaudhry B: Conceptualization, Project Administration, Resources, Supervision, Visualization, Writing - Review \& Editing

Competing interests: No competing interests were disclosed.

Grant information: This work was supported by grant funding from the National Centre for the Replacement, Reduction and Refinement of Animals in Research (NC3Rs; NC/L002000/1), and from Alpe D'HuZes (AdH)/KWF PROPER (UL2014-7058).

Copyright: (c) 2018 Hill D et al. This is an open access article distributed under the terms of the Creative Commons Attribution License, which permits unrestricted use, distribution, and reproduction in any medium, provided the original work is properly cited. Data associated with the article are available under the terms of the Creative Commons Zero "No rights reserved" data waiver (CC0 1.0 Public domain dedication).

How to cite this article: Hill D, Chen L, Snaar-Jagalska E and Chaudhry B. Embryonic zebrafish xenograft assay of human cancer metastasis [version 2; peer review: 2 approved] F1000Research 2018, 7:1682 https://doi.org/10.12688/f1000research.16659.2

First published: 22 Oct 2018, 7:1682 https://doi.org/10.12688/f1000research.16659.1 


\section{REVISED Amendments from Version 1}

The new version of this article has been updated to, confirm details of when and how the experiment is terminated; reference FIJI imaging software as a method of analysis; emphasise the importance of establishing a baseline for the invasion of different cancer cell lines and the use of tracer beads to evaluate movement associated with organ development; reference other uses of this model such as analysis of angiogenesis or cancer cell proliferation; document product codes of important materials used; and confirm details of how 3D printed moulds were created. A new version of Supplementary File 1 has been provided. Figure 3 has also been updated to account for the different analysis used.

See referee reports

\section{Research highlights}

\section{Scientific benefit(s):}

- Optimal xenotransplantation can be performed in zebrafish embryos at $48 \mathrm{hpf}$, allowing for a 72-hour period to model key stages of metastatic behaviour.

- Metastatic processes can be visualised at the single cell level.

3Rs benefit(s):

- Zebrafish embryos can be used to replace mouse xenograft models in early cancer metastasis research.

\section{Practical benefit(s):}

- Only a small number of cancer cells (100-200 cells per fish) are required.

- Use of fluorescent cell markers in conjunction with transgenic zebrafish lines allows for host cells to be distinguished from human cancer cells in real-time/in situ, avoiding the need for post-mortem immunocytochemistry.

- The zebrafish embryo assay is higher-throughput than mouse xenograft models.

\section{Current applications:}

- Studying tumour invasion and metastatic dissemination of different human cancer cell lines using time-lapse microscopy.

- Studying the invasion of human cancer cells into zebrafish blood vessels and in the formation of secondary tumours.

\section{Potential applications:}

- Studying the heterogeneity of tumours and cooperation of different cancer cells from patient-derived tumours.

- Studying the remodelling of the extracellular matrix during tumour invasion.

- As a screening assay to identify new agents/drugs that reduce the metastatic behaviour of cancer cells.

\section{Introduction}

Metastasis is a clinical term describing the spread of tumour cells from a primary location to distant sites. It is suggested that more than $90 \%$ of deaths from cancer are not caused by the primary tumour but by the direct effects of metastatic deposits and from the metabolic burden of a rapidly growing tumour cell mass (Jemal et al., 2011). Traditionally an orderly cascade of cellular behaviours was presumed to underlie the progression from a well circumscribed and localised tumour growth to distant spread, based on initial local invasion, entry into the vascular or lymphatic system, survival in those fluid channels followed by extravasation and colonisation in a distal site (Massagué et al., 2017). However, this orderly progression is not borne out by current research and the mechanisms of metastatic spread remain controversial. The role of epithelial to mesenchymal transformation (EMT) is unclear and plasticity of cells that metastasise and their relationship to the primary tumour cells, e.g. stem cells, remains the object of current research (Pandya et al., 2017). Furthermore, cancers do not appear to disseminate randomly, but exhibit tropism for specific organs, especially lung, liver and bone (Tarin, 2011). This observation, made over 100 years ago by Steven Paget, led to the "seed and soil" hypothesis which remains unproven. In clinical practice, surgical resection or local treatment of primary tumours is effective, but metastases remain difficult to treat. This is particularly evident for melanoma, where localised and slowgrowing metastatic deposits can appear long after apparent cure (Gershenwald \& Scolyer, 2018). Similarly, in prostatic cancer the primary site is rarely a clinical problem in comparison to the pain and pathological fractures from osteolytic vertebral deposits (Akakura et al., 1996).

Understanding the multi-step processes that regulate cancer metastasis will likely result in new therapeutics to benefit patients with a wide range of cancers at different stages of progression. Although in vitro systems, e.g. the artificial skin model for melanoma (Hill et al., 2015) can be highly effective for studying primary tumour behaviour, connected organ systems are needed to understand metastasis. The mouse has traditionally been used as a pre-clinical model organism to study cancer under the rationale that they are a mammalian species, with the same organ systems as humans. Although genetically modified animals do spontaneously develop tumours, the introduction of human tumour cells into other species, xenografting, is a vital pre-clinical tool that enables researchers to study tumour metastasis and evaluate drug responses (van Marion et al., 2016). Xenografts provide greater experimental control and can provide a direct translational link to the patient, particularly when the developmental origin of cancer remains unknown. However within a mouse, metastatic spread from xenografts often occurs late, well after the primary deposit has become distressing to the animal, and further pain can also result from the aggressive invasive nature of the metastases (Gómez-Cuadrado et al., 2017). Highly metastatic cell lines are often used to accelerate the development of metastatic tumours, but these may not reflect normal metastasis, and therefore several different lines must be used, requiring many more animals (Cruz-Munoz et al., 2008). It is sometimes possible to surgically remove the primary tumour prior to analysis of metastatic dissemination (Srivastava et al., 2014); however, this is often associated with excessive tissue damage requiring prolonged post-operative analgesia. Direct injection of cancer cells into the tail vein (Elkin \& Vlodavsky, 2001; Minn et al., 2005), heart (Kang et al., 2003), illiac artery (Bos et al., 2009; Wang et al., 2015), spleen (Morikawa et al., 1988), peritoneum (Chu et al., 2015) or tibia (Fisher et al., 2002) have all been used to model local metastatic behaviours, but the mouse model is limited since metastasising single cells cannot be tracked and only relatively large metastatic growths can be 
detected, precluding study of the earliest metastatic events. Furthermore, mouse models have also had limited success when predicting anti-cancer drug efficacy in human trials (Day et al., 2015; Kersten et al., 2017).

The zebrafish is a tropical bony fish which for over 30 years has been increasingly used in developmental biology and human disease modelling as it contains almost all human organ systems except lungs (Penberthy et al., 2002). The zebrafish genome has been sequenced and there is a high degree of conserved genes and genetic signalling pathways compared to humans (Howe et al., 2013). Importantly for the study of cancer metastasis, embryos are completely transparent, facilitating imaging at single cell level within developing organs whilst also imaging the entire animal. Furthermore, the majority of studies can be carried on early-stage embryos before they are capable of independent feeding, which for the zebrafish is widely considered to be 5 days post fertilisation (dpf), and protected under the Animals (Scientific Procedures) Act (ASPA) and EU Directive (2010/63/EU). The extra-uterine development of hundreds of eggs also permits a greater number of studies in genetically identical organisms. Since the first reported xenotransplantation of human cells into zebrafish (Lee et al., 2005), many laboratories have shown that zebrafish embryos are useful for the study of other facets of tumour biology including cancer-induced angiogenesis (Britto et al., 2018; Haldi et al., 2006; Nicoli et al., 2007); cancer cell invasion and metastasis (de Boeck et al., 2016; Marques et al., 2009); cancer stem cell growth (Bansal et al., 2014; Chen et al., 2017); interaction of cancer cells with the host (Feng \& Martin, 2015); and drug screening (Corkery et al., 2011; Gibert et al., 2013). Importantly, the development of human tumours and their response to chemotherapeutic treatment in zebrafish embryos is comparable to that observed in mouse xenograft assays (Fior et al., 2017). Additionally, while mouse xenograft models require immuno-deficient mice to prevent immune-rejection of the human cancer cells, the lack of a mature adaptive immune system within zebrafish embryos up to $14 \mathrm{dpf}$ allows analysis of human cancers without rejection (Lam et al., 2004).

In this article we describe the techniques for performing embryonic zebrafish xenograft experiments and demonstrate the utility of using zebrafish embryos as a model system for studying human cancer metastasis, in particular metastatic melanoma and prostate cancer. We highlight the advantages over mouse xenograft models and provide a practical experimental protocol showing how zebrafish embryos can be used as a replacement for mice to conveniently study metastatic tumour behaviour in the laboratory.

\section{Methods}

A full step-by-step protocol can be found in Supplementary File 1.

\section{Zebrafish husbandry}

Transparent Casper $\operatorname{Tg}(k d r l ; G F P)$ zebrafish were housed under standard conditions at $28.5^{\circ} \mathrm{C}$ (Westernfield, 2000). All animals were maintained under UK Home Office project licence 604548 according to the requirements of the Animals (Scientific
Procedures) Act 1986 of the UK Government and conformed to Directive 2010/63/EU of the European Parliament. Zebrafish eggs were collected by timed pair mating and incubated in E3 media at $28.5^{\circ} \mathrm{C}$ in air until 48 hours post fertilisation (hpf). A completed ARRIVE checklist can be found in Supplementary File 2. Embryos are maintained under anaesthesia where appropriate and killed prior to $120 \mathrm{hpf}$ using a schedule 1 method. For individual embryos this can be through destruction of the brain using forceps, or for larger numbers destruction of the brain can be assured using a polythene rolling pin.

\section{Human cell culture}

Human melanoma cells A375 (American Type Culture Collection (ATCC), Manassas, USA; RRID, CVCL_0132), as well as C8161 (RRID, CVCL_6813) and WM164 (RRID, CVCL_ 7928) (generously gifted by Professor Meenhard Herlyn, The Wistar Institute, Philadelphia, USA), or PC-3M-Pro4-mCherry prostate cancer cells (ATCC; RRID, CVCL_D579), were incubated at $33^{\circ} \mathrm{C}$ for 24 hours to precondition cells prior to staining with $1,1^{\prime}$-Dioctadecyl-3,3,3',3'-tetramethylindocarbocyanine perchlorate (DiI; Vybrant red fluorescent dye; Invitrogen, Paisley, UK) and injection into zebrafish embryos.

\section{Injection of cancer cells into zebrafish embryos}

Zebrafish embryos at $2 \mathrm{dpf}$ were immobilised using $1.2 \mathrm{mM}$ tricaine methanesulfonate, which is a water soluble, fast-acting anaesthetic agent. Zebrafish embryos were then embedded in a thin film of low-melting-point agarose to stabilise the fish in a lateral position. To investigate invasion of cancer cells from the extravascular compartment into the vasculature, approximately 250 Dil-labelled melanoma cells in a volume of $5 \mathrm{nl}$ were injected into the inferior section of the yolk sac. Similarly, to investigate tissue tropism of cancer cells, 250 DiI-labelled prostate cancer cells in a volume of $5 \mathrm{nl}$ were injected into the vein of Cuvier. Following injection, fish were carefully removed from the agarose/tricaine solution using Dumont No5 fine forceps and transferred individually into 96-well plate imaging chambers created from $1 \%$ agarose using 3D printed pins (Wittbrodt et al., 2014). Minor orientation was required and embryos were suitable for microscopic analysis within 2 hours of injection.

\section{Confocal microscopy}

Confocal images $(250 \mu \mathrm{m}$ total $\mathrm{z}$-depth) of each fish were captured at 0,24 and 72 hour time points, or every 15 mins for 5 hours for time-lapse imaging, using an inverted Leica SP8 confocal microscope (Leica Microsystems, GmbH Heidelberg, Germany) at $405 \mathrm{~nm}$ (blue FluoSpheres), $488 \mathrm{~nm}$ (green blood vessels) and $564 \mathrm{~nm}$ (red cells). The movement of DiI-positive melanoma cells was analysed using Volocity 3D Image Analysis Software (Volocity 6.3; PerkinElmer, Waltham, Massachusetts, USA) by manually measuring the two-dimensional distance moved by individual melanoma cells from site of injection. This analysis could alternatively be performed using ImageJ to measure the calibrated pixel distance. The number of RFP-expressing prostate cancer cells was analysed using ImageJ software version 1.8.0_112 (https://imagej.nih.gov/ij) to quantify the total area and intensity of RFP fluorescence. 


\section{Statistical analysis}

For the analysis of tissue-specific homing of prostate cancer cells, 2 dpf zebrafish embryos from a pool of embryos derived from several mated adult zebrafish pairs were randomly assigned to receive an injection of PBS, or an injection of cancer cells, into the vein of Cuvier. The experimental unit is the individual zebrafish embryo, and a sample size of 4 embryos per group was selected on the basis of a normal standard deviation set at $95 \%$ confidence level $(\mathrm{z}=1.96)$, a confidence interval (c) of 0.05 and assuming an effect size of $90 \%(p=0.9)$ based on pilot experiments, according to the formula: $n=(2 z(p)(1-p)) / 2 c$. Measurement of total RFP-fluorescence within confocal images was performed and analysed using two-tailed Student's t-test by a second researcher using GraphPad Prism 7 software (Graph Pad, San Diego, CA USA).

\section{Results}

\section{Local non-vascular metastatic spread}

The initial event in metastatic spread is the movement of an individual cancer cell from the tumour niche. This can be modelled using in-vitro systems such as skin organoids or the Dunn chemotactic chamber, but neither of these assays are suitable for measuring metastasis. In our zebrafish embryo xenograft model, we inject small deposits of fluorescently labelled human cancer cells into the yolk sac at $2 \mathrm{dpf}$, and track individual cells until $5 \mathrm{dpf}$ (Figure 1A). By using a zebrafish line with absent pigmentation it is possible to achieve excellent views throughout transgenic embryos with GFP-labelled endothelial blood vessels (green; $510 \mathrm{~nm}$ emission), ensuring injection of DiI-labelled A375 melanoma cells (red; $565 \mathrm{~nm}$ emission) into the extravascular compartment (Figure 1Bi), which directly migrate to peripheral sites (Figure 1Bii. Although embryos are normally allowed to develop at $28.5^{\circ} \mathrm{C}$ and human cells at $37^{\circ} \mathrm{C}$, a compromise at $33^{\circ} \mathrm{C}$ works well. The movement of individual melanoma cells from site of injection can be measured using ImageJ or Volocity image analysis software (Figure 1C).

\section{Intravasation of metastatic cells}

The ability to carry out time-lapse imaging on embryos affords the opportunity to examine individual cell movement. Injected embryos were lightly anaesthetised using tricaine and orientated in low-melting-point agarose. By focusing on the point of injection, DiI-labelled melanoma cells were visualised moving through the extravesicular compartment within the yolk sac of zebrafish embryos using low-voltage time-lapse confocal microscopy (Figure 2A and Supplementary Movie 1). A 3Drendering of the confocal image $\mathrm{z}$-stack was rotated to reveal the transverse section of the blood vessel showing a melanoma cell positioned between the zebrafish endothelial cells, indicating that this cell is directly within the blood vessel (Figure 2Ax and Supplementary Movie 2).

\section{Metastasis and the endothelium}

Haematological or lymphatic metastatic dissemination requires interaction with the endothelium during entry and exit. However, patients can also have cancer cells circulating in their blood that do not necessarily show metastases (Reymond et al., 2013). It is now recognised that metastasising cells exhibit

\section{A) \\ 2dpf fli-GFP Casper zebrafish embryo}

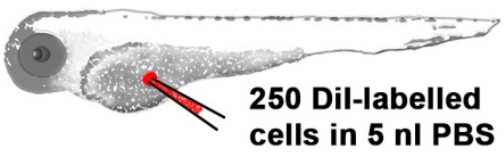

\section{2 hours at $33^{\circ} \mathrm{C}$}
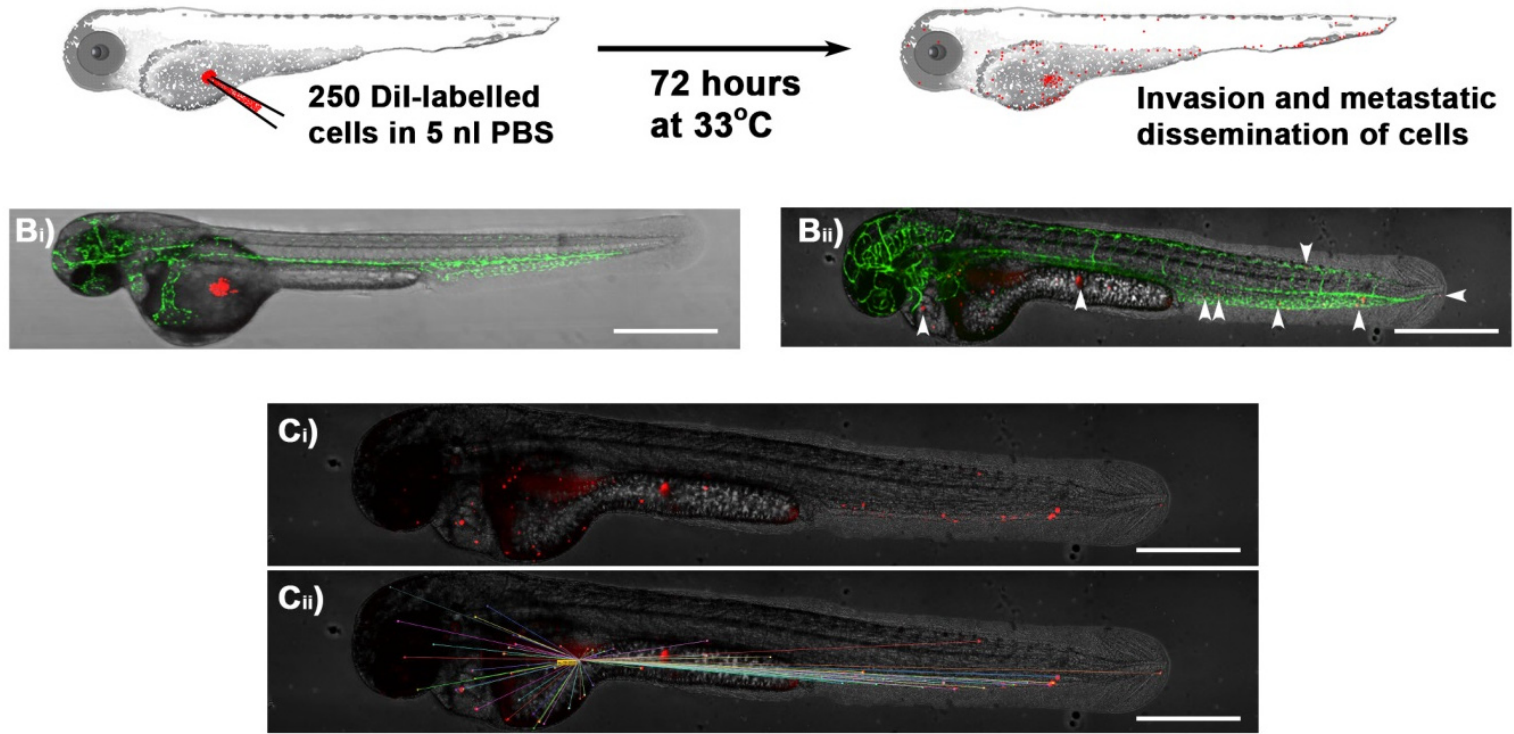

Figure 1. Schematic of xenograft assay and analysis of cell migration. A) Site-specific injection (depicted into the yolk sac) of Dil- or RFP-labelled (Red) cancer cells in $5 \mathrm{nl}$ PBS into 2 dpf zebrafish embryos is followed by incubation of zebrafish for 72 hours at $33^{\circ} \mathrm{C}$ and subsequent imaging analysis of invasion and metastatic dissemination of cancer cells. B) Approximately 250 Dil-labelled A375 melanoma cells 0 hrs (Bi) and 72 hrs (Bii; white arrows indicate position of melanoma cells) after injection into the yolk sac of Tg(kdrl-GFP) Casper zebrafish (Green blood vessels). C) Confocal z-stack images are used to visualise red Dil fluorescence of melanoma cells within zebrafish (Ci) and the distance from injection site measured using Volocity image analysis software (Cii); Scale bar $=500 \mu \mathrm{m}$. 

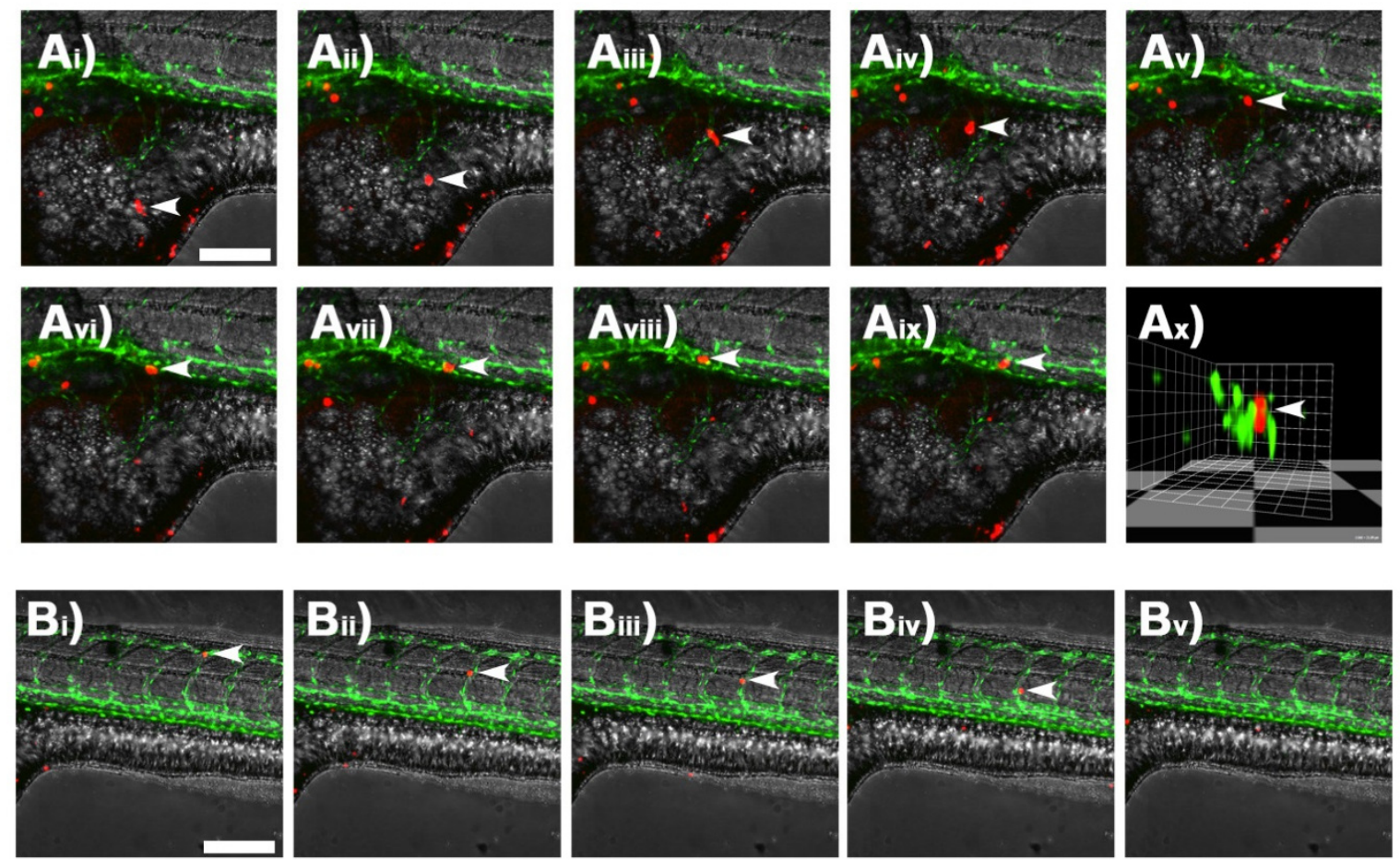

Figure 2. Single cell tracking by time-lapse confocal microscopy. Ai-ix) Confocal z-stack images taken at 15 minute intervals showing an individual Dil-labelled A375 melanoma cell (white arrows) migrating within the yolk sac of a casper zebrafish embryo and interacting with a GFP-tagged blood vessel. Ax) 3D-render of image Aix rotated to show the transverse section through the GFP-tagged blood vessel with Dil-labelled melanoma cell indicated by white arrows. Bi-v) Confocal z-stack images taken at 15 minute intervals showing an individual Dil-labelled melanoma cell (white arrows) within the GFP-tagged blood vessels of a casper zebrafish embryo. Scale bar $=150 \mu \mathrm{m}$.

sticking and rolling as they interact with the endothelium, and surface molecules such as selectins and CD44 are implicated. The zebrafish embryo xenograft model shows potential to be an extremely powerful tool in understanding the relationship between the surface biology of tumour and endothelial cells. Time-lapse confocal microscopy at 15-minute intervals readily captured melanoma cells as they demonstrated sticking and rolling behaviours on the surface of vascular endothelium (Figure 2B and Supplementary Movie 3) clearly suggesting a specific interaction of the human melanoma cells with zebrafish endothelial cells.

Tumour cells can also be directly injected into the circulation of developing zebrafish via the vein of Cuvier providing a tractable model of metastatic cancer cell-endothelial interaction during vascular exit. This is particularly important in some tumours that do not readily enter the vasculature, but do have tissue tropic exit routes. For example, the prostate cancer cell line PC-3M-Pro4-mCherry does not metastasise from the yolk sac, but when injected into the circulation these cells seed in the caudal hematopoietic tissue of the zebrafish tail where they proliferate, suggesting a specific microenvironmental niche favourable for tumour development (Figure 3A, B).

\section{Heterogeneity of metastatic cell behaviour}

A specific benefit of embryonic zebrafish over other larger preclinical laboratory models is that several experiments can be carried out in parallel on the same microscope stage. This allows screening of a library of pharmacological candidates, but importantly evaluation of different metastatic cell types, which may be primary cell lines derived directly from patients. This is important as heterogeneity between or within patient tumours may be important in metastatic behaviour. We have seen this in our own melanoma work, where C8161 cells disseminated widely throughout the yolk sac (Figure 3C) while WM164 cells formed a localised tumour-like mass with fewer melanoma cells invading the yolk sac (Figure 3D). Co-injection of tracer beads can be used to distinguish passive developmental associated movement from active migration and invasion of cancer cells. Metastatic A375 cells were found in the distal tail vessels, whilst very few C8161 and WM164 cells were found in the tail and other regions of the zebrafish by $72 \mathrm{hpf}$, indicating C8161 and WM164 cells have a reduced capacity to invade blood vessels, which may limit their metastatic potential.

These vital imaging-based assays used in combination with the ability to genetically modify zebrafish or apply pharmacological agents represent important new tools and approaches to understand these metastatic processes at a cellular level.

Dataset 1. Raw images used to generate figures shown in this study

https://dx.doi.org/10.5256/f1000research.16659.d221978

Shown are images for Figures 1 and 3; images in Figure 2 were obtained from stills of Supplementary Movies 1-3. 

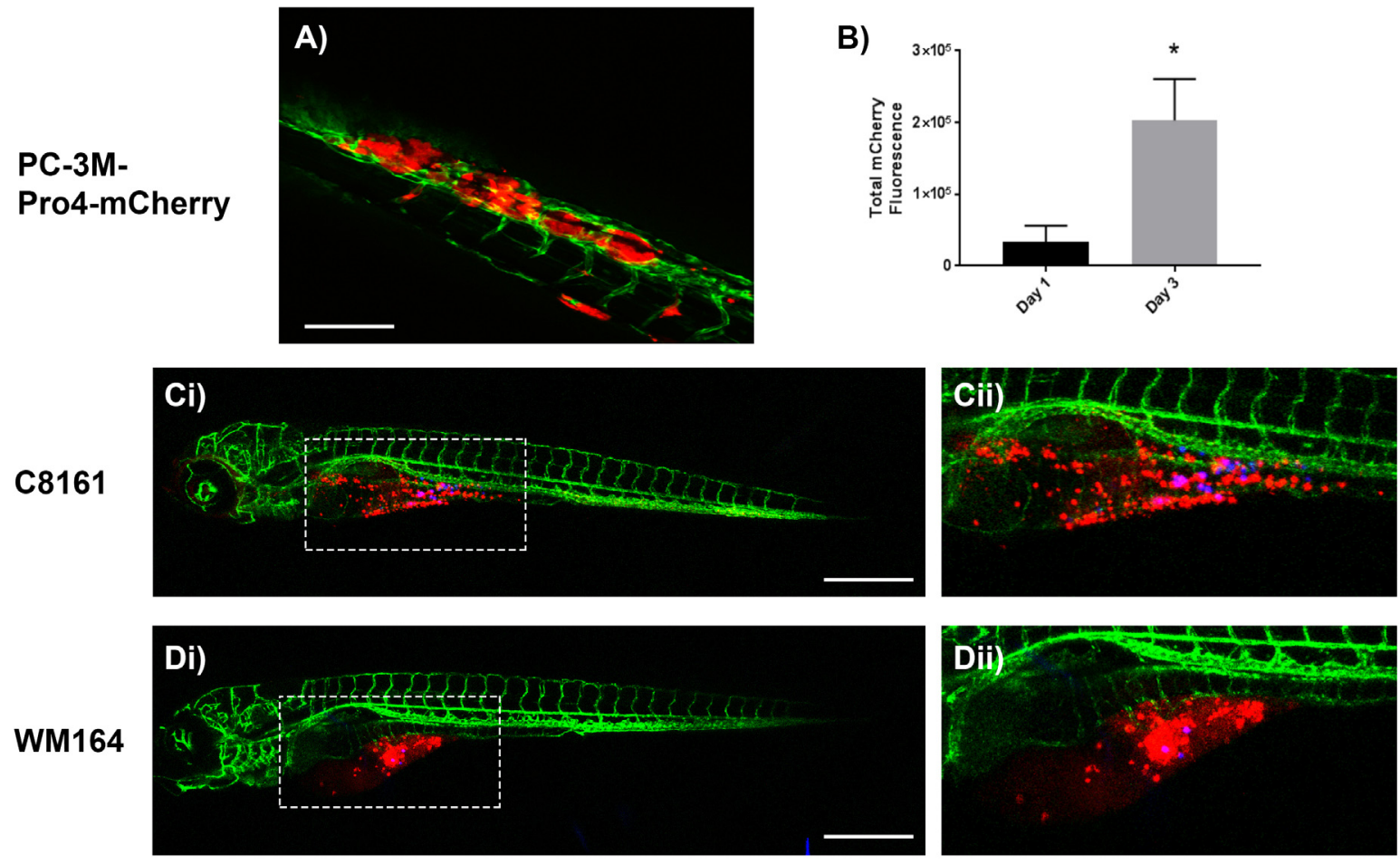

Figure 3. Representative confocal z-stack images of kdrl-GFP casper zebrafish embryos 72 hours after injection with human cancer cells. A) PC-3M-Pro4-mCherry prostate cancer cells injected into the duct of Cuvier form tumours in the caudal hematopoietic tissue of the zebrafish tail; Scale bar $=150 \mu \mathrm{m}$. B) Quantification of total mCherry fluorescence by prostate cancer cells after 1 and 3 days post injection; $n=4$, ${ }^{*} p<0.01,0.05 \mathrm{Cl}$, paired t-test. Ci-ii) C8161 and Di-ii) WM164 melanoma cells (stained with Red Dil dye) injected alongside FluoSpheres (Blue) into the yolk sac survive and invade throughout the yolk sac; Scale bar $=500 \mu \mathrm{m}$.

\section{Discussion}

We and others have shown that xenotransplantation of human cancer into zebrafish embryos can be optimally carried out at $48 \mathrm{hfp}$ when gastrulation is complete and the main body plan of the animal is established. The next 72 hours provides sufficient time frame to model key stages of metastatic behaviour, including local invasion, vascular entry, circulation and vascular exit. In this paper we have demonstrated how tumour invasion and/or metastatic dissemination by human cancer cells can be monitored through time-lapse microscopy. Most importantly, metastatic processes of single cells can be visualised at the earliest time points, which is not possible in a mouse model. The zebrafish embryonic xenograft of human cancer therefore directly replaces the need for using mouse xenografts and avoids welfare concerns associated with mouse models, including pain and suffering due to unexpected or excessive primary tumour growth. In the UK alone, it is estimated that over 550,000 mice are used each year for cancer research (UK Home Office statistics). On average 50 mice are used per study of cancer metastasis, and over the past 5 years there have been on average 900 publications per year in this area. We therefore estimate that 45,000 mice are used each year for research of cancer metastasis using mouse xenograft models, many of which could be replaced by embryonic zebrafish at unregulated stages of development, using the model described in this paper. To do this several historical concerns need to be addressed.
Experimentally, it is essential that following xenotransplantation human cells can be distinguished from host cells of the zebrafish. Whilst this can be achieved post-mortem by detecting human-specific antigens using immunocytochemistry (Bentley et al., 2015), the use of lipophilic fluorescent cell membrane stains in conjunction with zebrafish transgenic lines allows visualisation of cells both during time-lapse imaging and after tissue fixation. These methods provide equivalent quantification of xenografted cancer cell proliferation (Bentley et al., 2015).

It might be suggested that differences in cell size, microenvironmental niches and molecular signalling pathways between human patients and preclinical models (mice as well as zebrafish) could limit the relevance and translational value of data obtained from animal studies. However, our studies show that human cancer cells are able to invade zebrafish blood vessels and form secondary tumours, which can be inhibited by specific autophagy inhibition (Verykiou et al., 2018); while previous studies have shown that VEGF and CXCR4 signalling are conserved between human cancers and zebrafish (He et al., 2012; Tulotta et al., 2016). Nevertheless, further studies to characterise the response of human cells in the zebrafish model organism are required.

The future direction of research using zebrafish embryos for human xenograft studies will likely focus on strategies and methods to increase assay throughput and improve analysis of 
large data sets. These objectives will benefit from a number of technical innovations, such as devices to orientate the zebrafish for imaging (Wittbrodt et al., 2014) as well as automated quantification and analysis of tumour cell dissemination (Ghotra et al., 2012; Heilmann et al., 2015). The analysis of in-situ cancer cell proliferation could be improved by using techniques such as EdU incorporation or use of a transgenic cell cycle reporter such as FUCCI within cancer cells (Haass et al., 2014)

Stable cancer cell lines are often dramatically different from patient tumour cells and by definition have been selected for ease of maintenance in the laboratory environment. However, it is likely that heterogeneity and cooperation of cancer cells in patient tumours drives tumour invasion through remodelling of the extracellular matrix (Chapman et al., 2014). Thus, cancer is represented by cells that vary in their proliferative, invasive and metastatic phenotype, which contributes both to tumour growth and also emergence of drug resistance (Anderson et al., 2011). However, it is often not feasible to investigate the effect of tumour cell heterogeneity in mouse xenograft models as large numbers of patient primary tumour cells are required for successful engraftment. In contrast, a major advantage of the embryonic zebrafish xenograft assay is the capacity to accurately detect and monitor a small number of cells (100-200 cells per fish), including low-number cancer subpopulations such as cancer stem cells, drug-resistant cells or primary patient tumour tissue where only small numbers of cells can be recovered e.g. circulating tumour cells. Patient-derived tumour xenograft models are therefore a potential solution to the problem of limited intratumoural heterogeneity of cell line derived xenografts, which may also improve the accuracy of tumour drug-response studies.
It is becoming increasingly clear that no single pre-clinical model can substitute for actual human trials, and therefore as researchers we must continually reassess and adapt our model assays to improve their relevance, which will likely involve employing an approach that combines multicellular in vitro organoid assays (Hill et al., 2015) with both zebrafish and mouse in vivo studies. We suggest that this combinatorial approach will reduce the reliance on mouse xenograft models for the study of human cancer metastasis and drug screening. However, the challenge for translational cancer research will be to integrate the multitude of data from different model organisms to identify evolutionary conserved drug-tumour interactions between species so that we may select the most appropriate therapeutics that have the highest chance of providing an effective treatment for patients with cancer.

\section{Data availability}

Dataset 1. Raw images used to generate figures shown in this study. Shown are images for Figure 1 and Figure 3; images in Figure 2 were obtained from stills of Supplementary Movie 1Supplementary Movie 3. DOI: https://doi.org/10.5256/ f1000research.16659.d221978 (Hill et al., 2018).

\section{Grant information}

This work was supported by grant funding from the National Centre for the Replacement, Reduction and Refinement of Animals in Research (NC3Rs; NC/L002000/1), and from Alpe D’HuZes (AdH)/KWF PROPER (UL2014-7058).

The funders had no role in study design, data collection and analysis, decision to publish, or preparation of the manuscript.

\section{Supplementary material}

Supplementary File 1. Complete step-by-step protocol for Zebrafish xenograft of human cancer cells.

Click here to access the data

\section{Supplementary File 2. Completed ARRIVE checklist.}

Click here to access the data

Supplementary Movie 1. Representative time lapse confocal movie showing active invasion of a DiI-labelled A375 melanoma cell through the yolk sac and into a kdrl-GFP labelled blood vessel of a Casper zebrafish embryo.

Images were taken every 15 minutes for 5 hours.

Click here to access the data

Supplementary Movie 2. 3D rendering of confocal movie showing active invasion of a DiI-labelled A375 melanoma cell through the yolk sac and into a kdrl-GFP labelled blood vessel of a Casper zebrafish embryo.

Transverse field of view through the blood vessel demonstrates that the red melanoma is within the green blood vessel and actively moving against the flow of blood.

Click here to access the data

Supplementary Movie 3. Representative time lapse confocal movie showing movement of a DiI-labelled A375 melanoma cell through a kdrl-GFP labelled blood vessel of a Casper zebrafish embryo.

Images were taken every 15 minutes for 5 hours.

Click here to access the data 
Akakura K, Akimoto S, Shimazaki J: Pain caused by bone metastasis in endocrine-therapy-refractory prostate cancer. J Cancer Res Clin Oncol. 1996; 122(10): 633-7.

PubMed Abstract | Publisher Full Text

Anderson AC, Pollastri MP, Schiffer CA, et al:: The challenge of developing robust drugs to overcome resistance. Drug Discov Today. 2011; 16(17-18): 755-61.

PubMed Abstract | Publisher Full Text | Free Full Text

Bansal N, Davis S, Tereshchenko I, et al.: Enrichment of human prostate cance cells with tumor initiating properties in mouse and zebrafish xenografts by differential adhesion. Prostate. 2014; 74(2): 187-200.

PubMed Abstract | Publisher Full Text | Free Full Text

Bentley VL, Veinotte CJ, Corkery DP, et al.: Focused chemical genomics using zebrafish xenotransplantation as a pre-clinical therapeutic platform for T-cell acute lymphoblastic leukemia. Haematologica. 2015; 100(1): 70-6.

PubMed Abstract | Publisher Full Text | Free Full Text

Bos PD, Zhang XH, Nadal C, et al:: Genes that mediate breast cancer metastasis to the brain. Nature. 2009; 459(7249): 1005-9.

PubMed Abstract | Publisher Full Text | Free Full Text

Britto DD, Wyroba B, Chen W, et al:: Macrophages enhance Vegfa-driven angiogenesis in an embryonic zebrafish tumour xenograft model. Dis Model Mech. 2018; 11(12): pii: dmm.035998.

PubMed Abstract | Publisher Full Text

Chapman A, Fernandez del Ama L, Ferguson J, et al.: Heterogeneous tumor subpopulations cooperate to drive invasion. Cell Rep. 2014; 8(3): 688-95. PubMed Abstract | Publisher Full Text | Free Full Text

Chen L, Groenewoud A, Tulotta C, et al:: A zebrafish xenograft model for studying human cancer stem cells in distant metastasis and therapy response. Methods Cell Biol. 2017; 138: 471-96.

PubMed Abstract | Publisher Full Tex

Chu Y, Tang H, Guo Y, et al.: Adipose-derived mesenchymal stem cells promote cell proliferation and invasion of epithelial ovarian cancer. Exp Cell Res. 2015; 337(1): 16-27.

PubMed Abstract | Publisher Full Tex

Corkery DP, Dellaire G, Berman JN: Leukaemia xenotransplantation in zebrafish--chemotherapy response assay in vivo. Br J Haematol. 2011; 153(6): 786-9.

PubMed Abstract | Publisher Full Text

Cruz-Munoz W, Man S, Xu P, et al:: Development of a preclinical model of spontaneous human melanoma central nervous system metastasis. Cancer Res. 2008; 68(12): 4500-5.

PubMed Abstract | Publisher Full Text

Day CP, Merlino G, Van Dyke T: Preclinical mouse cancer models: a maze of opportunities and challenges. Cell. 2015; 163(1): 39-53.

PubMed Abstract | Publisher Full Text | Free Full Text

de Boeck M, Cui C, Mulder AA, et al:: Smad6 determines BMP-regulated invasive behaviour of breast cancer cells in a zebrafish xenograft model. Sci Rep. 2016; 6: 24968 .

PubMed Abstract | Publisher Full Text | Free Full Text

Elkin M, Vlodavsky I: Tail vein assay of cancer metastasis. Curr Protoc Cell Biol. 2001: Chapter 19: Unit 19.2 .

PubMed Abstract | Publisher Full Text

Feng $Y$, Martin $P$ : Imaging innate immune responses at tumour initiation: new insights from fish and flies. Nat Rev Cancer. 2015; 15(9): 556-62.

PubMed Abstract | Publisher Full Tex

Fior R, Póvoa V, Mendes RV, et al.: Single-cell functional and chemosensitive profiling of combinatorial colorectal therapy in zebrafish xenografts. Proc Natt Acad Sci U S A. 2017; 114(39): E8234-e43.

PubMed Abstract | Publisher Full Text | Free Full Text

Fisher JL, Schmitt JF, Howard ML, et al.: An in vivo model of prostate carcinoma growth and invasion in bone. Cell Tissue Res. 2002; 307(3): 337-45.

PubMed Abstract | Publisher Full Tex

Gershenwald JE, Scolyer RA: Melanoma Staging: American Joint Committee on Cancer (AJCC) 8th Edition and Beyond. Ann Surg Oncol. 2018; 25(8): 2105-10. PubMed Abstract | Publisher Full Text

Ghotra VP, $\mathrm{He} \mathrm{S}$, de Bont $\mathrm{H}$, et al: Automated whole animal bio-imaging assay for human cancer dissemination. PLOS One. 2012; 7(2): e31281.

PubMed Abstract | Publisher Full Text | Free Full Text

Gibert $\mathrm{Y}$, Trengove MC, Ward AC: Zebrafish as a genetic model in pre-clinical drug testing and screening. Curr Med Chem. 2013; 20(19): 2458-66.

PubMed Abstract | Publisher Full Text

Gómez-Cuadrado L, Tracey N, Ma R, et al:: Mouse models of metastasis:

progress and prospects. Dis Model Mech. 2017; 10(9): 1061-74.

PubMed Abstract | Publisher Full Text | Free Full Text

Haass NK, Beaumont KA, Hill DS, et al.: Real-time cell cycle imaging during melanoma growth, invasion, and drug response. Pigment Cell Melanoma Res. 2014; 27(5): 764-776.

PubMed Abstract | Publisher Full Tex

Haldi M, Ton C, Seng WL, et al.: Human melanoma cells transplanted into zebrafish proliferate, migrate, produce melanin, form masses and stimulate angiogenesis in zebrafish. Angiogenesis. 2006; 9(3): 139-51.

PubMed Abstract | Publisher Full Text

He S, Lamers GE, Beenakker JW, et al.: Neutrophil-mediated experimental metastasis is enhanced by VEGFR inhibition in a zebrafish xenograft model. $J$ Pathol. 2012; 227(4): 431-45.

PubMed Abstract | Publisher Full Text | Free Full Text

Heilmann S, Ratnakumar K, Langdon E, et al:: A Quantitative System for Studying Metastasis Using Transparent Zebrafish. Cancer Res. 2015; 75(20): 4272-82. PubMed Abstract | Publisher Full Text | Free Full Text

Hill D, Chen L, Snaar-Jagalska E, et al:: Dataset 1 in: Embryonic zebrafish xenograft assay of human cancer metastasis. F1000Research. 2018. http://www.doi.org/10.5256/f1000research.16659.d221978

Hill DS, Robinson ND, Caley MP, et al.: A Novel Fully Humanized 3D Skin Equivalent to Model Early Melanoma Invasion. Mol Cancer Ther. 2015; 14(11): 2665-73.

PubMed Abstract | Publisher Full Text | Free Full Text

Howe K, Clark MD, Torroja CF, et al:: The zebrafish reference genome sequence and its relationship to the human genome. Nature. 2013; 496(7446): 498-503.

PubMed Abstract | Publisher Full Text | Free Full Text

Jemal A, Bray F, Center MM, et al:: Global cancer statistics. CA Cancer J Clin 2011; 61(2): 69-90.

PubMed Abstract | Publisher Full Text

Kang Y, Siegel PM, Shu W, et al.: A multigenic program mediating breast cancer metastasis to bone. Cancer Cell. 2003; 3(6): 537-49.

PubMed Abstract | Publisher Full Text

Kersten K, de Visser KE, van Miltenburg MH, et al:: Genetically engineered mouse models in oncology research and cancer medicine. EMBO Mol Med. 2017; 9(2): 137-53

PubMed Abstract | Publisher Full Text | Free Full Text

Lam SH, Chua HL, Gong Z, et al:: Development and maturation of the immune system in zebrafish, Danio rerio: a gene expression profiling, in situ hybridization and immunological study. Dev Comp Immunol. 2004; 28(1): 9-28. PubMed Abstract | Publisher Full Text

Lee LM, Seftor EA, Bonde G, et al:: The fate of human malignant melanoma cells transplanted into zebrafish embryos: assessment of migration and cell division in the absence of tumor formation. Dev Dyn. 2005; 233(4): 1560-70. PubMed Abstract | Publisher Full Text

Marques IJ, Weiss FU, Vlecken DH, et al:: Metastatic behaviour of primary human tumours in a zebrafish xenotransplantation model. BMC cancer. 2009; 9: 128. PubMed Abstract | Publisher Full Text | Free Full Text

Massagué J, Batlle E, Gomis RR: Understanding the molecular mechanisms driving metastasis. Mol Oncol. 2017; 11(1): 3-4.

PubMed Abstract | Publisher Full Text | Free Full Text

Minn AJ, Gupta GP, Siegel PM, et al:: Genes that mediate breast cancer metastasis to lung. Nature. 2005; 436(7050): 518-24

PubMed Abstract | Publisher Full Text | Free Full Text

Morikawa K, Walker SM, Nakajima M, et al: Influence of organ environment on the growth, selection, and metastasis of human colon carcinoma cells in nude mice. Cancer Res. 1988; 48(23): 6863-71.

PubMed Abstract

Nicoli S, Ribatti D, Cotelli F, et al.: Mammalian tumor xenografts induce neovascularization in zebrafish embryos. Cancer Res. 2007: 67: 2927-2931. PubMed Abstract | Publisher Full Text

Pandya P, Orgaz JL, Sanz-Moreno V: Modes of invasion during tumour dissemination. Mol Oncol. 2017; 11(1): 5-27.

PubMed Abstract | Publisher Full Text | Free Full Text

Penberthy WT, Shafizadeh E, Lin S: The zebrafish as a model for human disease. Front Biosci. 2002; 7: d1439-53.

PubMed Abstract

Reymond N, d'Agua BB, Ridley AJ: Crossing the endothelial barrier during metastasis. Nat Rev Cancer. 2013; 13(12): 858-70.

PubMed Abstract | Publisher Full Text

Srivastava K, Hu J, Korn C, et al:: Postsurgical adjuvant tumor therapy by combining anti-angiopoietin-2 and metronomic chemotherapy limits metastatic growth. Cancer Cell. 2014; 26(6): 880-95.

PubMed Abstract | Publisher Full Text

Tarin D: Cell and tissue interactions in carcinogenesis and metastasis and their clinical significance. Semin Cancer Biol. 2011; 21(2): 72-82.

PubMed Abstract | Publisher Full Text

Tulotta C, Stefanescu C, Beletkaia E, et al:: Inhibition of signaling between human CXCR4 and zebrafish ligands by the small molecule IT1t impairs the formation of triple-negative breast cancer early metastases in a zebrafish xenograft model. Dis Model Mech. 2016; 9(2): 141-53.

PubMed Abstract | Publisher Full Text | Free Full Text

van Marion DM, Domanska UM, Timmer-Bosscha $\mathrm{H}$, et al:: Studying cance metastasis: Existing models, challenges and future perspectives. Crit Rev Oncol Hematol. 2016; 97: 107-17.

PubMed Abstract | Publisher Full Text 
Verykiou S, Alexander M, Edwards N, et al.: Harnessing autophagy to overcome mitogen-activated protein kinase kinase inhibitor-induced resistance in metastatic melanoma. Br J Dermatol. 2018.

PubMed Abstract | Publisher Full Text

Wang H, Yu C, Gao X, et al.: The osteogenic niche promotes early-stage bone

colonization of disseminated breast cancer cells. Cancer Cell. 2015; 27(2): 193-210.

PubMed Abstract | Publisher Full Text | Free Full Text
Westernfield M: A Guide for the Laboratory Use of Zebrafish (Danio Rerio). 4th Edition. 2000

Reference Source

Wittbrodt JN, Liebel U, Gehrig J: Generation of orientation tools for automated zebrafish screening assays using desktop 3D printing. BMC Biotechnol. 2014; 14: 36.

PubMed Abstract | Publisher Full Text | Free Full Text 


\section{Open Peer Review}

\section{Current Peer Review Status:}

\section{Version 1}

Reviewer Report 12 November 2018

https://doi.org/10.5256/f1000research.18207.r39773

(C) 2018 Feng $Y$. This is an open access peer review report distributed under the terms of the Creative Commons Attribution License, which permits unrestricted use, distribution, and reproduction in any medium, provided the original work is properly cited.

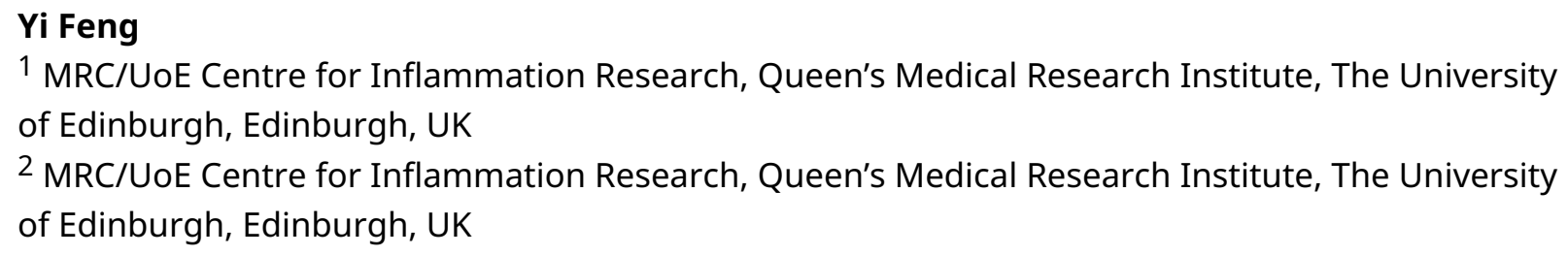

Zebrafish embryo xenograft model is a widely adopted method to study many aspects of cancer cell behaviour in vivo. A variety of protocols that differ by injection site, incubating temperature and down stream phenotype chosen, have been used in the field. So far, there is still a lack of a publicly available, detailed standard protocol, which new users could follow. The current methodology paper provides a very detailed, easy to follow protocol for xenograft fluorescent labeled cancer cells in the yolk sac and vein of Cuvier in 2 days old embryos and how to monitor cancer cell dissemination following the graft to assess their metastasis potential. This paper would be of benefit to anyone who wants to try out the zebrafish embryo xenograft model.

The step by step protocol could include more details that would make it more user friendly for someone who is new to fish models.

Material section:

1. It would help if more details were given for the following reagents such as Cat number because there could be multiple products available under a similar name: Low-melting point agarose, Borosilicate glass capillaries, Ultrafine forceps. What size?, 96-well plate. Are these with a glass bottom?

2. 3D printed mould to create imaging chambers - this is referred to in another paper without any details given. Perhaps they could expand on how they made it or obtained it? The imaging chamber is a key aspect and for this protocol to be "high through-put" more details would really help the reader.

Protocol steps

1. Once embryos transferred into imaging chamber, the authors indicate that the embryos will be maintained in $150 \mathrm{ml} 1 X$ E3 media containing $1.2 \mathrm{mM}$ tricaine for 72 hours. This could have detrimental effects on embryos. The authors should comment on whether any adverse effects were observed and how to avoid them. 
2. One of the Optional steps: "Tracer beads can be used to label the original injection site and to distinguish active tumour cell migration from passive development associated movement that occurs when tissues and organs within the yolk sac grow." To my mind it is very important for the initial set up of the model, as different cancer cell lines display different metastasis capacities and the tracer beads can be found expanding from the original injection site due to various reasons that the authors pointed out. So the use of tracer bead would help to set up a baseline index for passive expansion, true cancer cell invasion and metastasis that can then be evaluated according to the baseline parameter. The authors could perhaps comment more on their experience of using tracer beads in the main text of the paper.

The main text of the paper

In the main text the authors nicely presented three examples of what biological features can be captured using confocal imaging analysis following graft. It would be very helpful if they could elaborate more on each of the models, presenting more details on what parameters could be established from each model.

Model 1 (figure $1 \mathrm{Cii}$ ) cancer cell dissemination. It seems that 2D distance is used instead of 3D and there is no mention of the size of each cell cluster that appeared to be metastatic growth. The authors should explain more extensively why they choose such a parameter and whether there are other potential parameters that one could measure to assess dissemination of cancer cells.

Model 2 (figure 2) intravasation and distal metastasis are extremely rare events according to other publications (Roh-Johnson M, et al), perhaps authors could comment on how frequently they can capture intravasation or cancer cells within blood vessels? Perhaps provide some information on their experience with different cell lines in their intravasation capacity.

Model 3 (Figure 3 A,B) injecting into the vein of Cuvier is similar to mouse tail vein injection where cancer cells are grafted directly into the blood stream. This allows for study of the capacity of cancer cell extravasion and proliferation in distal tissues to establish metastic growth. Data presented in (Figure $3 \mathrm{~A}, \mathrm{~B}$ ) using fluorescent intensity as read out for cancer cell proliferation (same for C, D), which is quite a crude way of quantification. I wonder if it is possible to use more precise methods such as EdU incorporation or pH3 staining, ki67 staining or PCNA staining? Perhaps authors could share their experiences of make some comments on other ways of evaluating the cancer cell proliferation in vivo after xenograft.

The authors focused on using the zebrafish xenograft models for metastasis analysis. Angiogenesis was one the first assays developed using zebrafish embryo xenograft model (Nicoli $\mathrm{S}$, et al). As a methodology, the protocol presented here can be adapted for angiogenesis analysis. Perhaps they could comment on how their protocol could be adapted for evaluating angiogenesis in vivo. There are new developments of the zebrafish embryo xenograft model for angiogenesis such as (Britto DD, et al) perhaps they could refer to this work in the introduction or discussion, so as to guide the reader to other and more specific examples.

\section{Are a suitable application and appropriate end-users identified? Yes}

If applicable, is the statistical analysis and its interpretation appropriate? 
Partly

Are the 3Rs implications of the work described accurately?

Yes

Is the rationale for developing the new method (or application) clearly explained?

Yes

Is the description of the method technically sound?

Yes

Are sufficient details provided to allow replication of the method development and its use by others?

Partly

If any results are presented, are all the source data underlying the results available to ensure full reproducibility?

Yes

Are the conclusions about the method and its performance adequately supported by the findings presented in the article?

Yes

Competing Interests: No competing interests were disclosed.

I confirm that I have read this submission and believe that I have an appropriate level of expertise to confirm that it is of an acceptable scientific standard.

Author Response 29 Nov 2018

David Hill

The authors would like to thanks Dr Feng for her insightful comments and suggestions. We detail below the additions and changes we have made specifically in response to this review:

1. We have incorporated all changes as suggested including: catalogue numbers of critical reagents and reference to angiogenesis; and mention of alternative postmortem analyses for cell proliferation.

2. Whilst we have only observed local movement of tracer beads, we have emphasised the importance of this quality control in the main manuscript.

3. For these studies we chose to analyse movements in a single plane and were able to find significant differences. However, with increased imaging time and use of lenses with limited depth of field, cells can be tracked in three dimensions. Caution should be employed as the light exposure in obtaining such image stacks may affect cell behaviour.

4. The capability of cancer cells to invade blood vessels was cell line dependent, for example, more than $80 \%$ of embryos injected with A375 cells had cancer cells within 
the blood vessels by 72 hours, while C 8161 and WM164 cells invaded blood vessels less frequently and also showed variable local movement. These preliminary studies indicate the utility of the zebrafish at pre-regulated embryonic stages to study key aspects of metastatic cancer spread.

Competing Interests: No competing interests were disclosed.

Reviewer Report 06 November 2018

https://doi.org/10.5256/f1000research.18207.r39771

(C) 2018 Hurlstone A. This is an open access peer review report distributed under the terms of the Creative Commons Attribution License, which permits unrestricted use, distribution, and reproduction in any medium, provided the original work is properly cited.

\section{Adam Hurlstone}

${ }_{1}^{1}$ Division of Cancer Studies, School of Medical Sciences, Faculty of Biology, Medicine and Health, The University of Manchester, Manchester, UK

2 Division of Cancer Studies, School of Medical Sciences, Faculty of Biology, Medicine and Health, The University of Manchester, Manchester, UK

I enjoyed reading this methodology paper which lays out clearly steps required to achieve successful xenotransplantation in zebrafish embryos and how subsequent growth and dissemination of cancer cells can be monitored.

The attached method protocol would be improved by inclusion of the below details:

Explain how to remove embryos from agarose using forceps

Indicate an appropriate model of microtitre plate for imaging purposes with an inverted microscope (does imaging require glass bottom plates or a certain grade of plasticware?) Specify where they obtained the plastic pin mold: have they manufactured it, requested it, or purchased it?

Comment on whether $72 \mathrm{~h}$ incubation in anesthetic is detrimental to embryo health/development

Which image analysis modules/tools were used in Velocity and Image J. Mention whether default parameters were selected or otherwise? Why 2D rather than 3D distances were calculated using Velocity? Velocity is relatively expensive proprietary software and may not therefore be widely accessible, whereas Image $\mathrm{J}$ is free. Could the whole analysis not be undertaken with Image J?

Specify an appropriate method of ensuring destruction of the embryos within $120 \mathrm{hpf}$

Turning to the rest of the manuscript:

Explain what metrics would be captured by the analysis depicted in Fig $1 \mathrm{~B}$ and present a representative graph. Mean/median migration distance? Is there a way of distinguishing between several small clusters of cells or a few larger ones? 
Specify the cell line used for Fig 2. How efficient is the model for capturing intravasation events? How many cells are captured intravasating per hour per embryo?

The presentation and analysis of data in Fig 3B is inappropriate as these are not independent populations of cells. A line graph and linear regression is the appropriate analysis. Does proliferation contribute to the expansion of cells in the caudal hematopoietic tissue?

It would be of value to include a statement describing the distribution of fluospheres injected either into the yolk or into the duct of cuvier

Are a suitable application and appropriate end-users identified?

Yes

If applicable, is the statistical analysis and its interpretation appropriate?

Partly

Are the 3Rs implications of the work described accurately?

Yes

Is the rationale for developing the new method (or application) clearly explained?

Yes

Is the description of the method technically sound?

Partly

Are sufficient details provided to allow replication of the method development and its use by others?

Partly

If any results are presented, are all the source data underlying the results available to ensure full reproducibility?

Yes

Are the conclusions about the method and its performance adequately supported by the findings presented in the article?

Yes

Competing Interests: No competing interests were disclosed.

I confirm that I have read this submission and believe that I have an appropriate level of expertise to confirm that it is of an acceptable scientific standard.

Author Response 29 Nov 2018

David Hill

The authors would like to thanks Dr Hurlstone for his thorough and inciteful review of our article. 
1. We have made suggested changes to clarify methodology and correct typographical errors in our article, including details of consumables and of pin-mould manufacture. Importantly, applying forceps to break the agarose away from the embryo allows its release into surrounding media. Toxicity of tricaine was not observed in our studies, but if there are concerns it should be excluded with a specific experimental control. Embryos were killed using a schedule 1 method (destruction of the brain). However, for post-mortem histological analysis, cooling and fixation in 4\% PFA was also used.

2. Whilst we used commercially available software, we also recommend use of the Fiji implementation of imageJ (https://fiji.sc/), which contains tools for measurement and tracking.

3. The cell line used for Figure 2 was the parental A375 human melanoma cell line. We have modified the figure legend to reflect this.

4. We have updated our analysis of Figure 3B to reflect that the same cell populations are measured at two time points by using a paired t-test rather than a student's t-test, and have updated Figure 3 and the legend for Figure 3 accordingly.

5. We have also included a reference (Verykiou et al., 2018) in the main text. We have used this method of analysis to measure the distance invaded by MEKi-resistant A375 melanoma cells. The use of nuclear-localised fluorescent proteins allow individual cells within a cluster to be distinguished, while the use of membrane dyes are ideal for analysis of primary tumour cells, low-number tumour subpopulations and transient events such as intra/extravasation or interaction of tumour cells with host cells and stroma.

Competing Interests: No competing interests were disclosed.

The benefits of publishing with F1000Research:

- Your article is published within days, with no editorial bias

- You can publish traditional articles, null/negative results, case reports, data notes and more

- The peer review process is transparent and collaborative

- Your article is indexed in PubMed after passing peer review

- Dedicated customer support at every stage

For pre-submission enquiries, contact research@f1000.com 